\title{
Efficacy and safety of ultrasound-guided internal jugular vein catheterization in low birth weight newborn
}

\author{
Fernando Montes-Tapia ${ }^{\mathrm{a}, *}$, Antonio Rodríguez-Taméz ${ }^{\mathrm{a}}$, Idalia Cura-Esquivel ${ }^{\mathrm{a}}$, Itzel Barreto-Arroyo ${ }^{\mathrm{a}}$, \\ Adolfo Hernández-Garduño a , Isaías Rodríguez-Balderrama ${ }^{\mathrm{a}}$, José Quero ${ }^{\mathrm{b}}$, Manuel de la O-Cavazos ${ }^{\mathrm{a}}$ \\ a Department of Pediatrics, Hospital Universitario, Universidad Autónoma de Nuevo León, Av. Madero y Gonzalitos s/n, Monterrey, N.L. 66451 \\ b Facultad de Medicina, Universidad Autónoma de Madrid, C/Arzobispo Morcillo 4 Madrid, Madrid, ES 28029
}

\section{A R T I C L E I N F O}

\section{Article history:}

Received 1 March 2016

Received in revised form 16 May 2016

Accepted 21 May 2016

\section{Key words:}

Internal jugular vein

Catheterization

Ultrasound

Low-birth weight newborn

\begin{abstract}
A B S T R A C T
Background: Central venous catheterization is not the first choice of vascular access in neonates. Success depends on the size of the vessel and the skill of the health professional performing the procedure. The internal jugular vein provides a predictable path for central venous cannulation, although it is more difficult to cannulate infants than adults and even more difficult in smaller newborns.

Methods: We conducted a prospective study in 100 newborns, in which a $4 \mathrm{Fr}$ ultrasound-guided central venous catheter was placed in the right internal jugular vein (RIJV). The study population was low birth weight (LBW) newborns $<2500$ g, very low birth weight (VLBW) newborns $<1500 \mathrm{~g}$ and extremely low birth weight (ELBW) newborns $<1000 \mathrm{~g}$.

Results: There were $53 \%$ female patients, mean gestational age was 31 weeks, mean weight $1352 \mathrm{~g}$ and the CVC was placed at a mean of 12 days of extrauterine life. Birth weight distribution was 39\% LBW; 33\% VLBW and 28\% ELBW. A mean of two (1-8) attempts were necessary with a procedure duration of 16.8 (10-40) minutes. Success of RIJV catheterization was $94 \%$. One attempt was necessary in $50 \%$ and up to 5 attempts in $95.7 \%$. Success by weight was VLBW, 97.2\%; ELBW, 92.9\%; LBW, 91.7\%. A venous hematoma occurred in 5\% of cases.

Conclusions: Ultrasound-guided RIJV cannulation with real-time visualization to gain access to the central venous circulation in low birth weight newborns is effective and safe.
\end{abstract}

(C) 2016 Elsevier Inc. All rights reserved.
The most frequently performed invasive procedure in a neonatal intensive care unit is placement of an intravascular catheter [1]. With the advancements in technology and better prenatal care and neonatal therapy, the survival of low weight newborn patients is greater every day. Some of these infants will require a catheter for monitoring blood pressure, drawing blood samples, and delivering fluids and drugs [2,3].

Central venous catheterization is not the first choice of vascular access in neonates. The first choices include peripheral lines, umbilical catheters, and central venous access through a peripheral vein. Success in achieving these accesses depends on the size of the vessel and the skill of the health professional performing the procedure. When these options for venous access are not possible, a central venous line is considered $[2,4,5]$.

Traditionally central lines are inserted in neonates by venous cutdown [6] or percutaneous puncture guided by anatomical reference. However, complications such as arterial puncture, pneumothorax,

\footnotetext{
* Corresponding author at: Universidad Autónoma de Nuevo Leon, Departamento de Pediatria, Hospital Universitario “Dr. José E. Gonzalez", Av. Madero y Gonzalitos s/n, Monterrey, Nuevo Leon, Mexico, CP64360.

E-mail address: fernando.montestp@uanl.edu.mx (F. Montes-Tapia).
}

hemothorax and even death have occurred secondary to catheterization by anatomical references, making this a high-risk procedure [7].

The internal jugular vein (IJV) provides a predictable path for central venous cannulation, but in children, a failed attempt of catheterization of the RIJV guided by anatomical references is inversely proportional to age, and it occurs in up to $60 \%$ of infants less than 3 months of age compared with adult patient populations (16\%) [8-10].

According to reports in the literature, anatomic factors are among the most frequent causes of failure of percutaneous insertion of a CVC, since in low birth weight newborns, the muscle and bone reference points are often difficult to palpate or locate $[11,12]$.

In adults, percutaneous catheterization guided by ultrasound has been widely reported and is today the technique of choice because of its efficacy and low complication rate $[13,14]$. In pediatric patients, the benefits of using ultrasound for the placement of a central venous access have also been demonstrated when compared with using anatomical references [15-19]. However, there are no data evaluating low weight newborns.

The objective of this study was to evaluate the efficacy and safety of ultrasound-guided RIJV access in a population of low-weight newborns attended in a neonatal intensive care unit in an academic teaching hospital in northeast Mexico. 


\section{Methods}

Newborns with a body weight less than $2500 \mathrm{~g}$ were included. A central venous catheter (CVC) was requested after conventional vascular accesses (umbilical, peripheral or femoral) had failed. The same pediatric surgeon (FMT) performed all ultrasound evaluations and procedures of the RIJV. The study was previously approved by the Institutional Ethics Committee (PE006) and in all cases; parent informed consent was obtained before the procedure. Newborns with any type of right cervical lesion were excluded. Those who had not undergone a RIJV ultrasound evaluation before the procedure were eliminated.

The study variables were gestational age and weight. Newborns were classified in three groups: low birth weight (LBW) newborns, 1501 to 2500 g; very low birth weight (VLBW) newborns, 1001 to $1500 \mathrm{~g}$; and extremely low birth weight (ELBW) newborns $<1000 \mathrm{~g}$.; data regarding sex, diagnosis, days of extrauterine life and type of ventilation, were recorded.

A MicroMaxx (Sonosite, Inc., Bothell, WA) portable ultrasound with a 4-8 Mhz transducer was used. Evaluation and vascular access were performed with the transducer in short-axis view (SAX), viewing the RIJV cross-sectionally. The time required for placement of the catheter was recorded, from the moment a sterile field was placed until fixation of the catheter to the skin. Also, the number of attempts needed for placement and the complications associated with the procedure were recorded.

\subsection{Insertion technique}

The patient was sedated intravenously with midazolam and fentanyl and placed in a supine position with a roll under the shoulders and the head rotated $40^{\circ}$ to the left. In VLBW and ELBW infants, the skin over the RIJV is stretched upwards with Micropore ${ }^{\circledR}$ (3M Company, Two Harbors, MI) in the cephalic and caudal directions. The skin traction method was performed to prevent collapse of the internal jugular vein [20] (Fig. 1). A 4 Fr. double lumen CVC was used, however the length varies

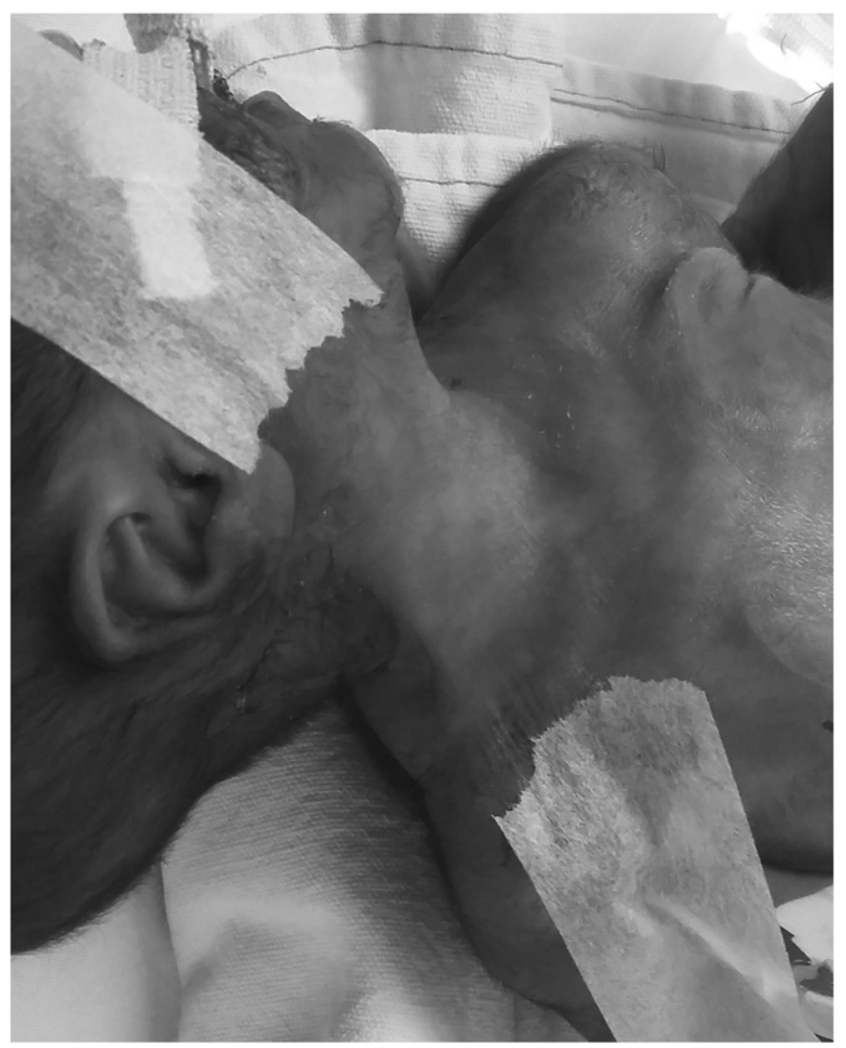

Fig. 1. The skin traction method in a patient of $740 \mathrm{~g}$, the skin over the RIJV is stretched upwards with Micropore ${ }^{\circledR}$ in the cephalic and caudal directions. according to availability in the hospital, $4 \mathrm{~cm}$ and $8 \mathrm{~cm}$ Cook Spectrum (Cook ${ }^{\circledR}$ Cook Critical Care, Bloomington, IN) or $13 \mathrm{~cm}$ (Arrow ${ }^{\circledR}$ International, Inc. USA).

Using an aseptic technique, sterile dressing and local anesthesia with $1 \%$ lidocaine, a puncture was made with real-time ultrasound guidance.

RIJV puncture was done by transfixion with a short 22-gauge intravenous catheter for LBW infants and a 24-gauge in VLBW and ELBW infants (Fig. 2). A 0.018" guidewire was used in LBW infants and a Runthrough ${ }^{\mathrm{TM}}$ 0.014" intravascular microguide (Terumo Medical Corporation, Japan) in VLBW and ELBW infants. A different caliber guidewire was used to ensure canalization of the RIJV in very small infants.

The catheter was introduced using the Seldinger technique and it was fixed with 4-0 polypropylene. A chest X-ray was taken to confirm the location of the catheter tip.

\subsection{Statistical method}

Statistical analysis was performed using IBM Statistics 19 for Windows.

Continuous variables were reported measures of central tendency and dispersion; and proportions for nominal or categorical variables. A stratified analysis based on body weight was performed according to the three groups (LBW, VLBW and ELBW). For the variable number of attempts and success of the procedure of placing a CVC in the RIJV, a comparative analysis was performed according to the weight of the subjects using the Mann-Whitney test, considering a $P$ value $<.05$ as a statistically significant difference.

\section{Results}

One hundred newborns with a birth weight below $2500 \mathrm{~g}$ were included during the period of August 2009 to December 2011. Of the total, $53 \%$ were females. According to gestational age, $96 \%$ were premature, and of these, $19 \%$ were extremely premature. Mean gestational age was $31 \pm 3.3$ weeks; mean weight was $1352 \pm 458 \mathrm{~g}$, and CVC placement was at $12 \pm 14$ days of extrauterine life. Based on weight, $39 \%$ were LBW infants (1501-2480 g), 33\% were VLBW infants (1030-1470 g), and 28\% were ELBW infants (540-960 g). At the time of the procedure, $73 \%$ had assisted ventilation. The diagnoses at the moment of CVC placement were sepsis $39 \%$, hyaline membrane disease $23 \%$, necrotizing enterocolitis $14 \%$, postsurgical $10 \%$, and other diagnoses in $14 \%$.

The anteroposterior cross-sectional diameter of the RIJV in the study population was $2.2 \pm 0.7 \mathrm{~mm}$ with a distance from the skin to the anterior wall of the vein of $3.6 \pm 1.1 \mathrm{~mm}$ [21]. A median of 2 (1-8) attempts was performed to achieve RIJV canalization, with the mean duration of the procedure being 16.8 (10-40) minutes. The overall success rate of CVC placement in the RIJV was 94\%. Failure occurred in 6 patients (6\%). Of these, in five patients (5\%), a non-pulsatile, non-expanding hematoma of the puncture site was found and failure to pass the guidewire occurred in one patient (1\%). All cases of hematoma were associated with puncture of the RIJV and none with puncture of the carotid. There were no cases of pneumothorax or hemothorax. Of the 94 patients in which canalization of the RIJV was achieved, in 47 (50\%) it was accomplished on the first puncture and in up to 5 attempts, 43 more newborns were cannulated successfully, with an accumulated success rate of $95.7 \%$ (Table 1 ).

In the six patients in which the procedure originally failed, the CVC was placed in the left internal jugular vein in 2 , the right femoral vein in 2 , the right subclavian vein in 1 and in the left subclavian vein in 1.

\subsection{Procedure success by groups}

The procedure was successful in $92.3 \%(\mathrm{n}=36)$ in the LBW group $(\mathrm{n}=39)$ and was accomplished on the first attempt in $55.6 \%(\mathrm{n}=$ 20) and after up to five attempts in 97.2\% $(\mathrm{n}=35)$. In VLBW ( $\mathrm{n}=$ $33)$ infants, the procedure was successful in $97 \%(n=32)$ and was accomplished on the first attempt in $43.8 \%(n=14)$ and after up to five 


\section{Download Full-Text Now}

\section{http://fulltext.study/article/4154684}

\section{fullText.study}

E Categorized Journals

Thousands of scientific journals broken down into different categories to simplify your search

\section{Full-Text Access}

The full-text version of all the articles are available for you to purchase at the lowest price

Free Downloadable Articles

In each journal some of the articles are available to download for free

Free PDF Preview

A preview of the first 2 pages of each article is available for you to download for free

\section{http://FullText.Study}

